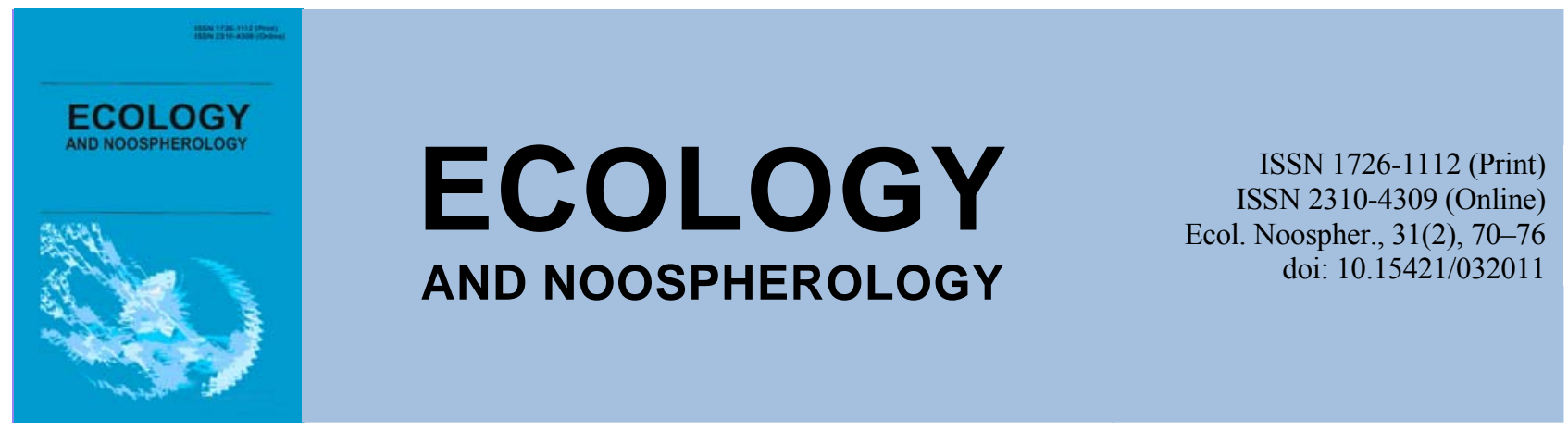

\title{
State-of-art and some ideas for future progress of bioassays with plants
}

\author{
O. I. Dzjuba*, O. P. Taran**, A. V. Viter*, N. V. Zaimenko* \\ *M. M. Gryshko National Botanical Garden of the NAS of Ukraine, Kyiv, Ukraine \\ **National University of Life and Environmental Sciences of Ukraine, Kyiv, Ukraine
}

Article info

Received 22.10.2020

Received in revised form 04.10 .2020

Accepted 11.11.2020

M. M. Gryshko National Botanical Garden of the NAS of

Ukraine, 1 Tymiryazevska str.,

Kyiv, 01014, Ukraine.

Tel.: +38044-285-41-05

E-mail: viter_a@ukr.net

National University of Life and Environmental Sciences of

Ukraine, 15 Heroiv Oborony str. Kyiv, 03041, Ukraine.
Dzjuba, O. I., Taran, O. P., Viter, A. V., Zaimenko, N. V. (2020). State-of-art and some ideas for future progress of bioassays with plants. Ecology and Noospherology, 31(2), 70-76. doi:10.15421/032011

Comparing with the trivial physical, physicochemical and chemical ways of the search of the agents of interest, the bioassays have the set of advantages, including the demand of less precision tools, less amounts of costs, labors and some other means. To date bioassays have formed the separate domain with its own theoretical basis, including classification, systematization, methodology, and meta-research. The present review analyzes the major spheres of the application of bioassays, such as environmental monitoring, quality control of foods. Bioassays contribute to the studies of the properties of plant metabolites, the peculiarities of the influence of various agents with potentials of toxicity, genotoxicity, neurotoxicity, mutagenicity, teratogenicity, endocrine disruption, etc. Bioassays not only enable the identification of stimuli by the specificity of structure (from atomic to supramolecular level), but also explore the stimuli functionally - in sense of the diversity of biological effects. This research approach is built on the indicators, which belong to the vast range of levels of living matter: from macromolecules to multi-cellular organisms. Great attention in this paper is paid to the parameters, detected in the process of bioassays, also to the methods and related instruments. We divide the methods into general physical, general chemical, general biologic and complex ones. The series of challenges to be researched in future are highlighted. They are: 1) elaboration of the investigatory option, which would be the same with the quantitative tests in chemistry; 2) the integration of the ideas of conventional bioassays with the ideas of bioindication and biolocation; 3) extension of the knowledge about correlation of distinct biological effects, induced by stimuli. Ultimately, bioassays are proved to be the actively developing domain of knowledge.

Keywords: bioassays; stimulus; method; technique; identification; effect

\section{Introduction}

The scientific and practical investigators commonly face the tasks of the identification of the agents with less known properties. The insufficiency of knowledge seriously restricts the opportunities of the search of such agents by means of trivial chemical, physicochemical or physical ways. At the same time bioassays have the advantages, as they require less input characteristics of the sought agent, and give the possibility to satisfy with those agent's properties, which are required no precision tools for their determination. The additional advantages of bioassays are the saving of costs, labors and some other means.

For these reasons the research methods, based on bioassays, get increasingly widespread assays not only in biology, but also in other branches of scientific explorations, in the industry, the applied monitoring of environment and food, in the medicine and sports. This trend encourages us to systemize the current knowledge in the field of bioassays.

In the present review we analyze the following aspects: 1) theoretical principles of bioassays; 2) environments or spheres of application; 3) phenomena under studies; 4) identifiable parameters; 5) indicators (in other words, test-objects (Saha, 2002)); 6) methods and instruments. Finally, we unravel the prospective research directions and those which are connected with bioassays.

Bioassays always have belonged to instrumental basis for allelopathy. The Ukrainian scientists, such as S. I. Chornobryvenko, N. I. Prutenska, A. M. Grodzynskyy (Grodzynskyy, 1973; Grodzynskyy et al., 1987; Yurchak, 2006), P. A. Moroz (1990), worked much at the elaboration of the bioassays for the specific needs of allelopathy. In general, despite of modern allelopathy adopts actively the advanced chemical and biological assays, the informational value of the conventional bioassays still doesn't decline.

\section{Theoretical principals}

Some authors make a point of the methodological issues, particularly on the fundamental ideas, which underpin bioassays. Thus, G. Prinsloo et al. (2017) list the promises and pitfalls, which are inherent to the in vitro-bioassays, applied in the trials of botanicals: 1) the type of assays and biological effects available; 2) false-positives, false-negatives and 
confounding factors; 3) matrix and combination effects; 4) extrapolation of in vitro data to the in vivo situation; 5) when to use and when not to use bioassays; 6) identification of active constituents.

Recently, the science has faced with the problem of the abandonment of all additive predictive-type models in the field of the study of synergism, particularly between the proteins. In contrast, F. S. Walters et al. (2016) assert the idea, 1) that the additivity models can remain useful assessment tools; 2) that an appropriately designed interaction study will never systematically underestimate the existence of synergism, irrespective of which additivity model (or none at all) may be used. Authors advise two beneficial steps for the analysis of experimental data from the point of view of synergism to follow: 1) the select of testing model; 2) avoid using bioassay methods which may result in excess response heterogeneity.

An important issue in the lion share of the tests in biology is the significance of dilution. From this perspective J. Tu \& P. Bennet (2017) analyze the following issues: 1) selectivity of bioassays; 2) matrix effects; 3) minimum required dilution; 4) endogenous levels of healthy and diseased populations. Such analysis assists to elucidate the advantages and disadvantages of the experiments, based on the parallelism, under their application for the evaluation of matrix effects.

\subsection{Issues of classification and systematization}

In turns the review of D. V. Sotnikov et al. (2018) offers the set of criteria for the classification of the wide range of those bioassays (predominantly based on the immunochemical systems), which are reported in the recent publications.

\subsection{Methodological issues}

The theoretical principles are closely connected with the issues of methodology. The series of the publications emphasize on the methodic aspect of bioassays, e. g. on the step-by-step description of the procedure of the analyses for the detection of toxic metabolites. D. M. Bürkholder et al. (2001) notice, that in the absence of purified standards of toxins from Pfiesteria species, fish bioassays can be reckon as the gold standard. This approach works well under the detection of the toxic Pfiesteria strains in the natural water of estuaries as well as in the sediment samples. The testing procedure includes the following steps: 1) isolation of the toxic strains of Pfiesteria (or other potentially, as-yet-undetected, toxic Pfiesteria or Pfiesteria-like species) from fish-killing bioassays with natural samples; 2) growing the clones with axenic algal prey; 3) retesting the isolates in a second set of fish bioassays. Taking into account the wide diversity of conditions, where samples are taken, under the modeling of bioassays it's worth to use the flexible meanings of temperature, salinity, light, and other factors. On the basis of the comparative analysis of more than two thousands of bioassays authors argue that fishes can't be substituted with algae, because the last are much less relevant indicator for the toxic Pfisteria strains.

\section{Fields of knowledge, explored by bioassays}

\subsection{Areas and environments of application of bioassays}

Bioassay-based models are applied in order to characterize:

1) sites of environment (Hassan et al., 2016; Iqbal et al., 2016), particularly:

1.1) atmosphere air (Kojima et al., 2018);

1.2) hydrosphere (Bürkholder et al., 2001; Weiss et al., 2017; Ghribi et al., 2019), including potable water (Leusch et al., 2017), wastewaters (Jirova et al., 2016);

1.3) soils (Essimbekova et al., 2014) and bottom sediments (Bürkholder et al., 2001);

2) internal environments of living organisms (Kojima et al., 2018), including those

2.1) in medical investigations (Essimbekova et al., 2014);

2.2) in sports (Copper et al., 2013);

3) products of labor, particularly those, which are connected with agriculture and food (Copper et al., 2013; Nishi et al., 2015; Hassan et al., 2016; Kojima et al., 2018; Starodub et al., 2018a);
4) man's wastes, particularly flue gas samples from incinerators (Kojima et al., 2018).

The environmental monitoring is driven mostly by the needs to control the agent of the different structural level (from separate chemical elements (Chapman et al., 2013) to supramolecular structures, prions (Giles et al., 2017) with the potential of mostly adverse influence on the biota and human.

The interests of the examinations of living organisms are determined by the exploration of the trends of the induction of the pathogenesis of diverse kinds, and are of great importance because of the control of inexpedient doping of sportsmen (Copper et al., 2013) and drug administration. This issue is connected with plant biochemistry, because some botanicals have been prohibited by the World Anti-Doping Agency (Cohen et al., 2019).

In turn, the need of the quality control of the target product and wastes of human activities comes from the assessment of risks for the human health and for the biota.

\subsection{Phenomena under studies}

Bioassays encompass several important areas of interest. Thus, one of them is the recognition of many phenomena and sometimes the deepened acquisition of knowledge in order to detail the characteristics of certain phenomenon.

Bioassays became the widespread mean for the research of 1) the causes and progress of carcinogenesis (Ito et al., 1996; Alden et al., 2011; Osimitz et al., 2013) 2) the properties of botanicals for the diverse applications (Agarwal et al., 2014; Prinsloo et al., 2017) and 3) the metabolites of quarantine weed Ambrosia artemisiifolia (Brückner et al., 2003); as well as for 4) the transcriptomic analyses (Nishi et al., 2015); 5) the elucidation of the influence of known and little-familiar agents on the organ-specific accumulation of toxins, the impairment of ontogenesis, genotoxic, mutagenic, teratogenic, and neurotoxic effects (Jirova et al., 2016; Du Gas et al., 2017; Ghribi et al., 2019), endocrine disruptions (Jirova et al., 2016; Tian et al., 2017; Zhang et al., 2018); 6) the improvement of the comprehension about the properties of substances and products of known nature (Osimitz et al., 2013). Besides plant indicators were applied under the investigation of the participation of the vector insects in the propagation of infection (Manachini et al., 2007), and Gammarus fossarum was involved for the research of the trends of the biodistruction of plant litters (Zubrod et al., 2017).

A. Agarwal et al. (2014) address the significance of bioassays from the standpoint of obtaining of intermediate results, since the lasts often foster the following research, regardless of the principles, purposes, and subjects. Intermediate results are evolved from the exploration of the botanicals, analyses of the interaction between the preparations and recipient organisms, the determination of the mechanisms of interaction. The researchers consider that the bioassays of plant materials are not only cognition interests, but also attractive for purposes the fractionation of bioactive products.

\section{Peculiarities of bioassay procedures}

Above we concerned the general features, characterizing the range of phenomena and notions. Usually, routes for the description of the general features run through the clarification of the knowledge about more specific concepts and parameters. We will highlight the last issue below.

\subsection{Sought stimuli}

It sounds expediently to distinguish two divisions for the stimuli, which are sought under bioassays. The first division covers the stimuli with ascertained structures or they are known forms, which serve the parameters of search. In the second case stimuli are identified due to specific functional properties, while the structural accuracy becomes collateral.

The identification of the form of sought object on the atomic level is often undertaken in course of the analyses of soil (e. g., Pb, Zn: (Chapman et al., 2013)). In turn the task of the characterization of the diverse environments motivates the 
needs in surveillance of the organic compounds by their form (Xu et al., 2014). Cobamines - the unique cofactors, essential for animal and human are an example of the groups of compounds, observed by bioassays. Cobamines comprises vitamin $\mathrm{B}_{12}$ and structurally related molecules. In some cases these substances are not beneficial, as they can exhibit unfavorable influence, e. g., under the contamination of nutritive media; and the especial interests of the cobamines' detection comes just from this reason (Crofts et al., 2014). The examples of other identifiable compounds include lactic acid within the root exudates (Wen et al., 2018), dimethyl, diethyl, diallyl and dipropyl phtalates (Sun et al., 2019), brevetoxins (Fleming et al., 2007), tenzauronic acid - mycotoxin of Alternaria alternata (Zhou et al., 2019), various herbicides, particularly glyphosate (Hong et al., 2017), and monocrotophos (Tian et al., 2017; Zhang et al., 2018). Besides, viruses (Manachini et al., 2007) and prions (Giles et al., 2017) belong to the stimuli of more complex level.

The functional explorations, based on bioassays, provide the indication of the agents of the impairment of genomes (Lakhansky \& Hendrickx, 1981; Iqbal et al., 2016; Khan et al., 2019; Wijeyaratne \& Wadasinghe, 2019); the disruptors of human or animal hormonal processes (Cooper et al., 2013; Jirova et al., 2016; Leusch et al., 2017); allergens (Nishi et al., 2015), particularly skin disease pathogens (Turkeltaub, 1989), surfactant toxins (Mudriy \& Debrivnaya, 1996). Also functionoriented bioassays facilitate the tracing of toxic forms among the inorganic and organic $\mathrm{Fe}_{3} \mathrm{O}_{4}$ nanoparticles (Mashjoor et al., 2018), poisons within food (Nishi et al., 2015) and aquatic ecosystems (Bürkholder et al., 2001; Jirova et al., 2016). Moreover, such bioassays examine the herbicidal properties of hentriacontane, 1-tetratriacontanol, $\beta$-sitosterol, momilactones $\mathrm{A}$ and $\mathrm{B}$, tricin, and $\beta$-sitosterol-3-O-beta-D-glucoside, extracted with ethyl acetate from the rice hulls (Chung et al., 2005); xanthyletin, 3-(1',1'-dimethylallyl)-xanthyletin, chalepensin, ammirin, chalepin,2'-isopropyl-psoralene, asarinin, fargesin, 4,5-epoxi- $\beta$-caryophyllene, pellitorine, extracted from Stauranthus perforatus roots (Anaya et al., 2005); alachlor, diuron and their photo- and biotransformation products (Bonnet et al., 2007); fungal metabolites (Bataineh et al., 2008); the plant toxicity of three pyranocoumarins and two pyranochromones, elaborated by Prionosciadium watsonii (Valensia-Islas et al., 2002).

The mycotoxins, particularly within plant food, pose substantial hazard to human health and life, as they cause embryotoxic, teratogenic, mutagenic and carcinogenic effects. The problem of mycotoxins gets worse because of the risks of bioterrorism (Starodub et al., 2018b). Moreover, nowadays the increment of $\mathrm{CO}_{2}$ level in atmosphere leads to more acidic state of many habitat conditions. This poses the threat of the propagation of fungi in the future world. The bioassays, designed to solve this problem, will be dedicated in some following sections of this paper.

Bioassays open the possibility of the detection of diverse substances, which behave like cytokinins (Biddington \& Thomas, 1973; Sciuto et al., 1981; Serdyuk et al., 1995), gibberellins (Sciuto et al., 1981; Kinsman et al., 1975), androgens (Leusch et al., 2017; Cooper et al., 2013), progestagens, glucocorticoids, estrogens, and exhibit thyroidal activity (Leusch et al., 2017). The role of stimuli could be played not only by hormones, but also by their analogs, such as precursors and mimetics. Since the analogs mostly possess unknown chemical structure, their detection with the standard gas chromatography-mass spectrometry methods is impossible. In contrast, the in vitro-bioassays don't engage the structure of substances, but their ability to activate receptors.

\subsection{Identifiable parameters}

Often just the proving of the presence or absence of a stimulus gives very scarce information. The characterizing of the objects under examination through the parameters increases the qualitative level of the outcome of bioassays. The publications deal with the following structural parameters: abundance of cells (Serdyuk et al., 1995; Brückner et al., 2003; Wen et al., 2018), aberrations of chromosomes (Khan et al., 2019); nuclear abnormalities in root tip cell with the mitiotic index (Wijeyaratne \& Wadasinghe, 2019); coloration of root tip (Bataineh et al., 2008); seed germination (Brückner et al., 2003; Chung et al., 2005; Bataineh et al., 2008); growth, elongation of root (Anaya et al., 2005; Wijeyaratne \& Wadasinghe, 2019) and hypocotile (Pooam et al., 2019); pathological damages of some tissues and organs (Ghribi et al., 2019), e. g., and leaf brow spots (Zhou et al., 2019).

Far more informativity is achieved due to the set of functional parameters: senescence of leaves (Zahaiska et al., 2017); shoot and root growth rate (Bataineh et al., 2008); content of free amino acids (Bedernichek et al., 2017), betacianine (Kinsman et al., 1975; Elliot, 1979) and amaranthine (Sciuto et al., 1981); intracellular content of alanine (Monselise et al., 2011), microcystin and polysaccharides (Wen et al., 2018); bioaccumulation factor (Sun et al., 2019); light-dependent phosphorylation (Pooam et al., 2019); oxidative stress; II phase metabolism; lipoperoxidation; activities of acetohydroxyacid synthase (EC: 2.2.1.6) (Mao et al., 2018) catalase, glutathione-S-peroxidase, acetylcholinesterase (Ghribi et al., 2019), immune-related enzymes (peroxidase, superoxide dismutase, acid and alkaline phoshatases, $\beta$-glucuronidase) pharmaceutical properties (West et Crawford, 2016); DNA repair defective mutations (Khan et al., 2019); $\mathrm{EC}_{50}$ (Sun et al., 2019) and $\mathrm{IC}_{50}$ (Mao et al., 2018); the assessment of gene expression as well as intracellular signaling of humans under food impact (Nishi et al., 2015); the specificity of the accumulation of substances (particularly toxins) within some organs (Jirova et al., 2016).

\subsection{Indicators and conceptions in bioassays}

In this context 'indicators' reflect the means, which are necessary for the detection of certain stimulus. The analysis of indicators sounds to be advantageous through the division them into the level of the organization of living matter.

We highlight the receptors as the indicators of molecular level. Thus, the cryptochrome protein of Arabidopsis thaliana was demonstrated to be sensitive to the influence of magnetic field (Pooam et al., 2019).

The indicators of cellular level could be divided into the separate unicell organisms (Wieczerzak et al., 2016), including bacteria Azotobacter agilis (Mudriy \& Debrivnaya, 1996), Vibrio fischeri (Bonnet et al., 2007), infusorium Tetrahymena pyriformis (Lakhansky \& Hendrickx, 1981; Sauvant et al., 1995; Bonnet et al., 2007), algae (Brückner et al., 2003; Sun et al., 2019), e. g. Microcystis aeruginosa (Wen et al., 2018), and cells as the parts of multicellular organisms.

In turns, S.C.Weiss et al. (2017) cite the indicators of subcellular level.

Apparently, the bioassays with the whole organisms have the longest history. The higher plants are powerful means for the detection of heavy metals in soil (Chapman et al., 2013). For the purposes of soil exploration the set of species, including Acer rubrum, Allium cepa, Brassica rapa, Quercus rubra, and Trifolium pratense were selected. At the same time Vicia faba indicates the mutagens (Iqbal et al., 2016). The advantages of this species include seasonal independence, simplicity of karyotype observation, cheapness, alone with its more sensitivity as compare with other indicators, which require the similar term of assays. In contrast to other plant indicators $V$. faba could be applied without pretreatment.

Testing in virology is one more field, which applies higher plants. Thus, Bellis perennis, Centaurea cyanus, Lepidium sativum, Matricaria chamomilla, Papaver rhoeas, Pisum sativum, Saponaria ocymoides, Trofolium repens, T. pratense, and Zinnia elegans became infected under the inoculation with plum pox virus, but Achillea millefolium, Amaranthus retroflexus, Linum grandifollium var. rubrum, Lupinus polyphyllus, and Taraxacum officinale did not (Manachini et al., 2007).

Other properties of plants were examined with Allium cepa (Khan et al., 2019; Wijeyaratne \& Wadasinghe, 2019), 
Amaranthus caudatus (Kinsman et al., 1975; Serdyuk et al., 1995), A. hypochondriacus (Valensia-Islas et al., 2002; Brückner et al., 2003; Anaya et al., 2005), A. retroflexus (Chung et al., 2005; Bataineh et al., 2008; Zhou et al., 2019), A. tricolor (Elliot, 1979; Mao et al., 2018), Cyperus difformis, and Leptochloa chinensis (Chung et al., 2005), Echinochloa crus-galli (Valensia-Islas et al., 2002; Anaya et al., 2005), Fagopyrum esculentum (Mudriy \& Debrivnaya, 1996), Lemna pausicostata (Valensia-Islas et al., 2002; Chung et al., 2005; Monselise et al., 2011), Cucumis sativus, Lollium perenne, and Silybum marianum (Bataineh et al., 2008), Brassica campestris, and Sorghum sudanense (Mao et al., 2018), Agerantia adenophora, and Digitaria sanguinalis (Zhou et al., 2019).

Wheat leaves, amaranth and tobacco callus cultures work well for the detection of cytokinin activity (Dolezal et al., 2006; Zahaiska et al., 2017).

Several high plant species have been widely applied for the biologically-based screening of mutagens. J. Maluszynska with J. Juchimiuk (2005) list the most common methods, used in this research direction: 1) cytogenetic assays for the induction of damages in mitotic chromosomes, including the tests on Allium cepa, Crepsis capillaris, Hordeum vulgare, Pisum sativum, Tradescancia paludosa, and Vicia faba; 2) assays for the induction of micronuclei, particularly in root cells of $H$. vulgare and $V$. faba, and in chromosomes under the stage of tetrads during the meiosis in T. paludosa; 3 ) assays for the induction of mutations in genes, namely in the loci of the waxy pollen of various species, e. g. in Zea mays, of chlorophyll deficiency in $H$. vulgare, somatic mosaicism in Glycine max, as well as the mutations within anther filaments in T. paludosa, and diverse mutations in Arabidopsis thaliana; 4) assays for the induction of sister chromatid exchanges and somatic recombinations, which suggest the cytogenetic analysis of the frequency of sister chromatid exchanges in $V$. faba and C. capillaries, the analysis of the rate of homological combinations in transgenic A. thaliana, and the analysis of somatic mosaicism in G. max; 5) comet assay on the tissues of Nicotiana tabacum, $V$. faba, and some non-domesticated plant species.

Overall, no genetic assay provides the determination of all genotoxic effects. Thus, the kits of assays are required for the examination of these effects. Kit comprises the limit number of complementary validated assays (Kutsokon, 2010).

Note, that green chemistry as the direction in analytical work admits the application of multicellular organisms (yeasts, plants, invertebrates and vertebrates) alone with diverse unicell species (Wieczerzak et al., 2016).

\subsection{Methods and tools of bioassays}

Lack of the understanding of necessary methods and tools allows the discussion of the results of bioassays only, but makes it impossible the experimentation proper. Methods mean the peculiarities of procedures, particularly the elements of technique, experimental work. In turn talking about tools, we will specificate the facilities employed in this work. Nevertheless often the difference between these two concepts disappears, and the name of method derives from the name of the applied tools.

Some publications report about the general physical methods: amperometry, voltametry, conductometry, potentiometry, and colorimetry (Hassan et al., 2016), as well as the general chemical methods: high-performance thin-layer chromatography (Weiss et al., 2017), high-resolution gas chromatography/high-resolution mass spectrometry (Kojima et al., 2018). The other research deal with the general biological methods, particularly utilizing diverse bioobjects in vitro (Agarwal et al., 2014; Leusch et al., 2017; Prinsloo et al., 2017; Weiss et al., 2017).

The transition of bioassays to qualitatively higher level necessitates the works at the interface of several natural sciences.

Firstly, the procedures of bioassays widely employ 1) microbiologic techniques, e. g. microbial fuel cells (Weiss et al., 2017); 2) biophysical analyses, namely bioluminescent (Essimbekova et al., 2014), fluorescent, and micrometric ones
(Nishi et al., 2015; Weiss et al., 2017); 3) biochemical analyses, particularly based on ability of the inhibition of luminescent enzymes and acetylcholinesterase (Weiss et al., 2017).

The luminescent methods compel interest due to their rapidity (they take no more than $5 \mathrm{~min}$ ), high sensitivity, simplicity and safety of procedure, and possibility of automation of ecological monitoring. Note, that luminometer, required for the trials, is easily available (Essimbekova et al., 2014).

Fluorescence-based bioassays fall into the set of ways: 1) microarray/biochip assay; 2) fluorescence-based microarrays/biochips, such as 2a) antibody/protein microarrays; 2b) bead/suspension arrays; 2c) capillary/sensor arrays; 2d) DNA microarrays/polymerase chain reaction (PCR)-based arrays; 2e) glycan/lectin arrays; 2f) immunoassay/enzyme-linked immunosorbent assay (ELISA)-based arrays; $2 \mathrm{~g}$ ) microfluidic chips and tissue arrays (Nishi et al., 2015).

Biophysical phenomena are the basis of numerous observations on indicators on the one hand, and on the other hand the principles of the operation of complicated biophysical means of investigation, particularly the principles of biosensors and biochips (Alépée et al., 2014; Hassan et al., 2016), are built on the properties of indicators.

A lot of mycotoxins, having low molecular weight, could not be detected by immunological methods. It is possible to overcome this challenge by the employing of special immunobiosensors (Starodub et al., 2008a). For instance, the detection of mycotoxin T2, zearalenone, ochratoxin, patulin, and aflatoxin B2 is provided by the fiber optical SOSbiosensing with the application of recombinant C600 (pPLS-1) Escherichia coli cells on cellophane membrane for the contact of the analytical unit with the transducer surface (Starodub \& Taran, 2016).

Secondly, the development of knowledge, obtained in the course of bioassays, fuels the silico-research. We mean the achievements of computer simulation for the solving of problems and tasks, which are relevant to the goals of the trivial bioassays. The launching of the open PubChem repository contributed for the establishing of in silico-direction in bioassays. PubChem contents data on the bioactivity of small molecules and the agents of RNA interference. This repository provides free access to the convenient information, providing the intuitive tools for data analysis. In 2012 this knowledgebase contented 500 thousand descriptions of assay protocols, covering 5 thousand protein targets with the 30 thousand protein targets, and reporting over 130 million bioactivity outcomes. PubChem enables the application of web-based and programmatic tools for the collection, comparison, and analysis of biological test results. Moreover, PubChem has encouraged data submission by the explorers (Wang et al., 2012).

\section{Developing ideas of bioassays}

Bioassays are associated mostly with the analogs of the identification tests in chemistry (Vlasov et al., 1979). Distinct bioindicators often react differently to the equivalent exposure of the same stimulus. However, we don't know the studies, focused on the selection of the set of indicators for the graduation of the results of bioassay for the detection of certain stimuli. Such studies would elaborate the promise, relevant to the quantitative tests in chemistry.

The other prospect is 'bioassays in situ'. In the previous sections of this paper we discussed the most conventional idea, that bioassays are the tests for the detection of the separate physical, chemical or biotic stimuli by the sensitive biotic means of the different levels of structural organization: from biomolecules to whole organisms. On our opinion the idea of bioassay can be spread by the inclusion of the concepts of bioindication and biolocation. The options and attractive features of these research directions could be found in the fundamental works by Y. P. Didukh (2012), and A. M. Gorelov (2007). 
The marker species, populations and other units of living world have been used as the indicators of the state of ecosystems, i. e. for the characterization such parameters as disturbance, stability, resilience, susceptibility, infection background, etc. For example, free amino acids within postmortem plant metabolites in soils are treated by the Ukrainian scientists (Bedernichek et al., 2017) as the markers of the adaptive processes in the plant-soil system.

There are little works, based on the phenomenon of the parallel responses of the principally distinct bioindicators to impact of the same stimulus. One of these works ascertains the reliable correlative relationship between the modulation of some physiological processes, particularly the plants' reception of the derivatives of cytokinins from the outside the cell and anti-tumor effect of these substances on human body (Dolezal et al., 2018). Talking the current tendency to avoid and ban the animal testing, the development of the knowledge about the parallel responses deserves consideration, as the prospective direction of research with profound theoretical basis. The last is supported by the idea that the cells of even taxonomically remote organisms are built with the similar functional blocks on molecular level (Ugolev, 1985; Ivashkin et al., 1990), likewise the genetic codes of almost all biodiversity employ only five universal nucleotides.

\section{Conclusions}

Bioassays are the outstanding analytical mean, complementary to the high-precision measurements of the rate of bioactive physical factors, as well as the content of bioactive substances and aggressive biotic agents. To date the body of the knowledge about bioassays makes it possible to set the specific methodology alone with the theoretical generalizations. The toxication of environment and the pathogenesis, especially carcinogenesis, belong to the most common processes, which are explored by bioassays. Some bioassays serve for the determination of the stimuli with the known structure, whereas the others are oriented on the stimuli with given functional properties. The physical and chemical principles of analyses fail to examine the functional features of stimuli. At the same time, the tasks of bioassays are the determination of both the structural parameters of bioobjects and their functions, including the content of substances and gene expression. Bioassay-based modeling exploits the wide range of the structural levels of indicators: from molecules to whole organisms and populations. In some studies the populations are considered to be the markers of the state of ecosystems. The indicators of prokaryotic, fungal, plant and animal nature are known to be treated in bioassays. Some bioassays could be carried out with unassisted eye, although the larger body of bioassays utilizes the sophisticated techniques, which are commonly applied in the physics or chemistry. The biosensors and biochips must be the most advanced among these techniques. The analysis of the reviewed publications provides the evidence, that bioassays belong to the developing research fields. Thus, the set of theoretical and practical issues is to be revealed in future.

\section{References}

Agarwal, A., D'Souza, P., Johnson, T. S., Dethe, S. M., \& Chandrasekaran, C. (2014). Use of in vitro bioassays for assessing botanicals. Current Opinion in Biotechnology, 25, 39-44.

Alden, C. L., Lynn, A., Bourdeau, A., Morton, D., Sistare, F. D., Kadambi, V. J., \& Silverman, L. (2011). A critical review of the effectiveness of rodent pharmaceutical carcinogenesis testing in predicting for human risk. Veterinary Pathology, 48(3), 772-784.

Alépée, N., Bahinski, A., Daneshian, M., De Wever, B., Fritsche, E., Goldberg, A., Hansmann, J., Hartung, T., Haycock, J., Hogberg, H., Hoelting, L., Kelm, J. M., Kadereit, S., McVey, E., Landsiedel, R., Leist, M.,
Lübberstedt, M., Noor, F., Pellevoisin, C., Petersohn, D. Pfannenbecker, U., Reisinger, K., Ramirez, T., RothenRutishauser, B., Schäfer-Korting, M., Zeilinger, K., \& Zurich, M. G. (2014). State-of-the-art of 3D cultures (organs-on-a-chip) in safety testing and pathophysiology. ALTEX, 31(4), 41-77.

Anaya, A. L., Macías-Rubalcava, M., Cruz-Ortega, R., GarciaSantana, C., Sánchez-Monterrubio, P. N., HernándezBautista, B. E., \& Mata R. (2005). Allelochemicals from Stauranthus perforatus, a Rutaceous tree of the Yucatan Peninsula, Mexico. Phytochemistry, 66(4), 487-494.

Bataineh, S. M., Saadoun, I., Hameed, K. M., \& Ababneh, Q. (2008). Screening for soil streptomycetes from North Jordan that can produce herbicidal compounds. Polish Journal of Microbiology, 57, 297-305.

Bedernichek, T. Y., Zaimenko, N. V., Ivannikov, R. V. Loya, V. V. Anishchenko, V. M., Partyka, T. V., \& Khoyetskyy, P. B. (2017). Content of low-molecular-weight organic compounds in soils under Deshampsia antarctica and D. cespitosa (Poaceae). Ukrainian Antarctic Journal, 16, 123-128 (in Russian).

Biddington, N. L. ,\& Thomas, T. H. (1973). A modified Amaranthus betacyanin bioassay for the rapid determination of cytokinins in plant extracts. Planta, 111(2), 183-186.

Bonnet, J.-L., Bonnemoy, F., Dusser, M., \& Bohatier, J. (2007). Assessment of the potential toxicity of herbicides and their degradation products to nontarget cells using two microorganisms, the bacteria Vibrio fischeri and the ciliate Tetrahymena pyriformis. Environmental Toxicology, 22(1), 78-91.

Brückner, D. J., Lepossa, A., \& Herpai Z. (2003). Inhibitory effect of ragweed (Ambrosia artemisiifolia L.)inflorescence extract on the germination of Amaranthus hypochondriacus L. and growth of two soil algae. Chemosphere, 51, 515-519.

Bürkholder, J. M., Marshall, H. G., Glasgow, H. B., Seaborn, D. W. \& Deamer-Melia, N. J. (2001). The standardized fish bioassay procedure for detecting and culturing actively toxic Pfiesteria, used by two reference laboratories for atlantic and gulf coast states. Environmental Health Perspectives, 109(Supplement 5), 745-756.

Calabrese, E. J., \& Baldwin, L. A. (2000). Radiation hormesis: its historical foundations as a biological hypothesis. Human and Experimental Toxicology, 19(1), 41-75.

Chapman, E. E., Dave, G., \& Murimboh, J. D. (2013). A review of metal $(\mathrm{Pb}$ and $\mathrm{Zn})$ sensitive and $\mathrm{pH}$ tolerant bioassay organisms for risk screening of metalcontaminated acidic soils. Environmental Pollution (Barking), 179, 326-342.

Chung, I. M., Hahn, S. J., \& Ahmad, A. (2005). Confirmation of potential herbicidal agents in hulls of rice, Oryza sativa. Journal of Chemical Ecology, 31, 1339-1352.

Cohen, P. A., Travis, J. C., Keizers, P. H. J., Boyer, F. E., \& Venhius, B. J. (2019). The stimulant higenamine in weight loss and sports supplements. Clinical Toxicology, 57(2), 125-130.

Cooper, E. R., McGrath, K. C., \& Heather, A. K. (2013). In vitro androgen bioassays as a detection method for designer androgens. Sensors (Basel), 13(2), 2148-2163.

Crofts T. S., Men Y., Alvarez-Cohen L., \& Taga M. E. (2014). A bioassay for the detection of benzimidazoles reveals their presence in a range of environmental samples. Frontiers in Microbiology, 5, Article 592.

Didukh, Y. P. (2012). Fundamentals of Bioindication. Kyiv: Naukova dumka Publ. (in Ukrainian).

Dolezal, K., Popa, I., Krystof, V. Spíchal, L., Fojtíková, M. Holub, J., Lenobel, R., Schmülling, T., \& Strnad, M. (2006). Preparation and biological activity of 6benzylaminopurine derivatives in plants and human cancer cells. Bioorganic and Medicinal Chemistry, 14, 875-884.

Du Gas L. M., Ross P. S., Walker J. Marlatt V. L., Kennedy C. J. (2017). Effects of atrazine and chlorothalonil on the 
reproductive success, development, and growth of early life stage sockeye salmon (Oncorhynchus nerka). Environmental Toxicology and Chemistry, 36(5), 1354-1364.

Elliott, D. C. (1979). Analysis of variability in the Amaranthus bioassay for cytokinins: Effects of water Stress on benzyladenine- and fusicoccin-dependent responses. Plant Physiology, 63, 269-273.

Esimbekova, E., Kratasyuk, V., \& Shimomura, O. (2014). Application of enzyme bioluminescence in ecology. Advances in Biochemical Engineering/Biotechnology, 144, 67-109.

Fleming, L. E., Kirkpatrick, B., Backer, L. C., Bean, J. A., Wanner, A., Reich, A., Zaias, J., Cheng, Y. S., Pierce, R., Naar, J., Abraham, W. M., \& Baden, D. G. (2017). Aerosolized red tide toxins (brevetoxins) and asthma. Chest, 131, 187-194.

Ghribi, R., Correia, A.T., Elleuch, B., \& Nunes, B. (2019). Testing the impact of contaminated sediments from the southeast marine coast of Tunisia on biota: a multibiomarker approach using the flatfish Solea senegalensis. Environmental Science and Pollution Research International, 29, 29704-29721.

Giles, K., Woerman, A. L., Berry, D. B., \& Prusiner S. B. (2017). Bioassays and inactivation of prions. Cold Spring Harbor Perspectives in Biology, 8(8), Article a023499.

Gorelov, A. M. (2007). Biolocation and Its Use in Studies of Plants. Kyiv, Fitosociotsentr Publ. (in Russian).

Grodzynskyy, A. M. (1973). Fundamentals of Chemical Interaction of Plants. Kyiv, Naukova dumka Publ. (in Ukrainian).

Grodzynskyy, A. M., Golovko, E. A., Horobets, S. A, Kostroma, Y. Y., Krupa, L. I., Prutenskaya, N. I., Serdyuk, L. S., Yurchak, L. D., \& Shrol T. S. (1987). Experimental Allelopathy. Kyiv, Naukova dumka Publ. (in Russian).

Hassan, S. H., Van Ginkel, S. W., Hussein, M. A., Abskharon, R., \& Oh S. E. (2016). Toxicity assessment using different bioassays and microbial biosensors. Environment International, 92-93, 106-118.

Hong, Y., Yang, X., Yan, G., Huang, Y., Zuo, F., Shen, Y., Ding, Y., \& Cheng, Y. (2017). Effects of glyphosate on immune responses and haemocyte DNA damage of Chinese mitten crab, Eriocheir sinensis. Fish and Shellfish Immunology, 71, 19-27.

Iqbal, M. (2016). Vicia faba bioassay for environmental toxicity monitoring: A review. Chemosphere, 144, 785-802.

Ito, N., Hasegawa, R., Imaida, K., Hirose, M., \& Shirai, T. (1996). Medium-term liver and multi-organ carcinogenesis bioassays for carcinogens and chemopreventive agents. Experimental and Toxicologic Pathology, 48(2-3), 113-119.

Ivashkin, V. T., Minasyan, G. A., \& Ugolev, A. M. (1990). Theory of Functional Blocks and Problems of Clinical Medicine. Leningrad, Nauka Publ. (in Russian).

Jirova, G., Wittlingerova, Z., Zimova, M., Vlkova, A.,Wittlerova, M., Dvorakova, M., \& Jirova, D. (2016). Bioindicators of wastewater ecotoxicity. Neuroendocrinology Letters, 37(Supplement1), 17-24.

Khan, S., Anas, M., \& Malik A. (2019). Mutagenicity and genotoxicity evaluation of textile industry wastewater using bacterial and plant bioassays. Toxicology Reports, 6 , 193-201.

Kinsman, L. T., Pinfield, N. J., \& Stobart, A. K. (1975). A gibberellin bioassay based on betacyanin production in Amaranthus caudatus seedlings. Planta, 127(2) 149-152.

Kojima, H., Takeuchi, S., Iida, M., Nakayama, S. F., \& Shiozaki, T. (2018) A sensitive, rapid, and simple DREcoScreen bioassay for the determination of PCDD/Fs and dioxin-like PCBs in environmental and food samples. Environmental Science and Pollution Research International, 25(8), 7101-7112.

Kutsokon N. K. (2010). Vegetable test-systems for genotoxicity detection. Visnyk of the National Academy of Sciences of Ukraine (4), 48-52 (in Ukrainian).
Lakhansky, T., \& Hendrickx, B. (1981). Tetrahymena pyriformis GL: a test system with multiple possibilities in the screening of genotoxic substances. Archives Belges de Medecine Sociale, Hygiene, Medecine du Travail et Medecine Legale, 39, 40-54 (in French).

Leusch, F. D., Neale, P. A., Hebert, A., Scheurer, M., \& Schriks, M. C. (2017). Analysis of the sensitivity of in vitro bioassays for androgenic, progestagenic, glucocorticoid, thyroid and estrogenic activity: Suitability for drinking and environmental waters. Environment International, 99, 120-130.

Małuszyńska, J. \& Juchimiuk, J. (2005). Plant genotoxicity: a molecular cytogenetic approach in plant bioassays. Arhiv za higijenu rada i toksikologiju, 56, 2, 177-184.

Manachini, B., Casati, P., Cinanni, L., \& Bianco, P. (2007). Role of Myzus persicae (Hemiptera: Aphididae) and its secondary hosts in plum pox virus propagation. Journal of Economic Entomology, 100, 1047-1052.

Mao, B., Gao, M., Chen, C., Li, Z., Zhang, H. Y., \& Zhang, Q. (2018). Design, synthesis and biological evaluation of novel N-nitrophenyl derivatives based on the structure of acetohydroxyacid synthase. Pesticide Biochemistry and Physiology, 145, 100-107.

Mashjoor, S, Yousefzadi, M., Zolgharnain, H., Kamrani E., \& Alishahi, M. (2018). Organic and inorganic nano- $\mathrm{Fe}_{3} \mathrm{O}_{4}$ : Alga Ulva flexuosa-based synthesis, antimicrobial effects and acute toxicity to briny water rotifer Brachionus rotundiformis. Environmental Pollution, 237, 50-64.

Monselise, E. B., Levkovitz, A., Gottlieb, H. E., \& Kost, D. (2011). Bioassay for assessing cell stress in the vicinity of radio-frequency irradiating antennas. Journal of Environmental Monitoring, 13, 1890-1896.

Moroz, P. ${ }^{\circ}$ A. (1990). Allelopathy in Orchards. Kyiv, Naukova dumka Publ. (in Russian).

Mudryı̆, I. V., \& Debrivnaia, I. E. (1996). The importance of using biological test objects in studying the toxicity of surface-active substances. Likars'ka Sprava, 3-4, 150-152 (in Russian).

Nishi, K., Isobe, S., Zhu, Y., \& Kiyama, R. (2015). Fluorescence-based bioassays for the detection and evaluation of food materials. Sensors (Basel), 15(10), 25831-25867.

Osimitz, T. G., Droege, W., Boobis, A. R., \& Lake, B. G. (2013). Evaluation of the utility of the lifetime mouse bioassay in the identification of cancer hazards for humans. Food and Chemical Toxicology, 60, 550-562.

Pooam, M., Arthaut, L. D., Burdick, D., Link, J., Martino, C. F., \& Ahmad, M. (2019). Magnetic sensitivity mediated by the Arabidopsis blue-light receptor cryptochrome occurs during flavin reoxidation in the dark. Planta, 249, 319-332.

Prinsloo, G., Papadi, G., Hiben, M.G., de Haan, L., Louisse, J., Beekmann, K., Vervoort, J., \& Rietjens I. M. C. M. (2017). In vitro bioassays to evaluate beneficial and adverse health effects of botanicals: promises and pitfalls. Drug Discovery Today, 22(8), 1187-1200.

Saha, G. M. (2002). Design and analysis for bioassays In Design Workshop Lecture Notes (pp. 61-76). Koltaka: Indian Statistical Institute.

Sauvant, M. P., Pepin, D., Bohatier, J., \& Groliere C. A. (1995). Microplate technique for screening and assessing cytotoxicity of xenobiotics with Tetrahymena pyriformis. Ecotoxicology and Environmental Safety, 32(2), 159-165.

Sciuto, S., Chillemi, R., Piattelli, M., \& Puglisi, G. (1981). Gibberellin- and cytokinin-like activities in marine algae from central Mediterranean. Bollettino della Societa Italiana Biologia Sperimentale, 15, 1590-1595.

Scott, A. P. (2013). Do mollusks use vertebrate sex steroids as reproductive hormones? II. Critical review of the evidence that steroids have biological effects. Steroids, 78(2), 268-281.

Serdyuk, O. P., Smolygina, L. D., Muzafarov, E. N., Adanin, V. M., \& Arinbasarov, M. U. (1995). 4-Hydroxyphenethyl alcohol - a new cytokinin-like substance from the 
phototrophic purple bacterium Rhodospirillum rubrum 1R. FEBS Letters, 365, 10-12.

Sotnikov, D. V., Zherdev, A. V., \& Dzantiev, B. B. (2017). Mathematical modeling of bioassays. Biochemistry (Moscow), 82(13), 1744-1766.

Starodub N. F, \& Taran M. V. (2016). Analysis of the efficiency of fiber optic SOS-type biosensor work at the different ways of the sensitive layer formation. Austin Journal of Biosensors and Bioelectronics, 2(2), 1022.

Starodub, N. F., Fedelesh-Morenetz, M. I., \& Savchuk, M. V. (2018a). Control of the genotoxicity of certain mycotoxins by a fiber optical SOS-type biosensors. World Journal of Engineering Research and Technology, 4(6), 199-205.

Starodub, N. F, Savchuk, M. V, Székács, A, \& Marty, J.-L. (2018b). Peculiarities of sample preparation for the determination of certain mycotoxins in grain products and fruits by immunobiosensor analysis. World Journal of Engineering Research and Technology, 4(3), 174-185.

Sun, C., Zhang, G., Zheng, H., Liu, N., Shi, M., Luo, X., Chen, L., Li, F., \& Hu, S. (2019). Fate of four phthalate esters with presence of Karenia brevis: Uptake and biodegradation. Aquatic Toxicology, 206, 81-90.

Tian, H., Sun, Y., Wang, H., Bing, X., Wang, W., \& Ru, S. (2017). Monocrotophos pesticide affects synthesis and conversion of sex steroids through multiple targets in male goldfish (Carassius auratus). Scientific Reports, 7(1), Article 2306.

Tu, J., \& Bennett, P. (2019). Parallelism experiments to evaluate matrix effects, selectivity and sensitivity in ligandbinding assay method development: pros and cons. Bioanalysis, 9(14), 1107-1122.

Turkeltaub P. C. (1989). Biological standardization of allergenic extracts. Allergologia et Immunopathologia, $17(2), 53-65$.

Ugolev, A. M. (1985). Evolution of Digestion and Principles of Evolution of Functions: The Elements of Modern Functionalism. Leningrad, Nauka Publ. (in Russian).

Valencia-Islas, N., Abbas, H., Bye, R., Toscano, R., \& Mata, R. (2002). Phytotoxic compounds from Prionosciadium watsoni. Journal of Natural Products, 65, 828-834.

Vlasov, V. P., Mazin, V. V., Turetskaya, R. H., Gus'kov, A. V., Komizerko, E. I., Lozhnikova, V. N., Yanina, L. I., Koff, E. M., Konopskaya, L. N., Sharikov, G. D., Filonova, V. P., Kefeli V. I. (1979). A complex method for determining of natural growth regulators. Primary analysis of corn immature seeds for activity of free auxins, gibberelins and cytokinins. Fiziologiya Rasteniy $=$ Journal of Plant Physiology (Moscow), 26(3), 648-655 (in Russian).

Walters, F. S., Graser, G., Burns, A., \& Raybould, A. (2018). When the whole is not greater than the sum of the parts: A critical review of laboratory bioassay effects testing for insecticidal protein interactions. Environmental Entomology, 47(2), 484-497.

Wang, Y., Xiao, J., Suzek, T. O., Zhang, J., Wang, J., Zhou, Z., Han, L., Karapetyan, K., Dracheva, S., Shoemaker, B. A., Bolton, E., Gindulyte, A., \& Bryant, S. H. (2012). PubChem's BioAssay database. Nucleic Acids Research, 40, D400-D412.

Weiss, S. C., Egetenmeyer, N., \& Schulz, W. (2017). Coupling of in vitro bioassays with planar chromatography in effectdirected analysis. Advances in Biochemical Engineering/Biotechnology, 157, 187-224.

Wen, Z., Yan, H., Shi, M., Chen B., \& Zhang, T. (2018). Inhibitory effect of the lactic acid leaching solution of Allium cepa L. on Microcystis aeruginosa. Wei sheng yan jiu = Journal of Hygiene Research, 47, 822-832 (in Chinese).

Wieczerzak, M., Namieśnik, J., \& Kudłak, B. (2016). Bioassays as one of the Green Chemistry tools for assessing environmental quality: A review. Environment International, 94, 341-361.

Wijeyaratne, W. M. D. N, \& Wadasinghe, L. G. Y. J. G. (2019). Allium cepa bio assay to assess the water and sediment cytogenotoxicity in a tropical stream subjected to multiple point and nonpoint source pollutants. Journal of Toxicology, Article N 5420124.

Xu, T., Close, D., Smartt, A., Ripp, S., \& Sayler, G. (2014). Detection of organic compounds with whole-cell bioluminescent bioassays. Advances in Biochemical Engineering/Biotechnology, 144, 111-151.

Yurchak, L. D. (2006). Allelopathy: Retrospective outlook, present state and perspectives of investigations. Introduction of Plants, (4), 12-23 (in Ukrainian).

Zahajská, L., Nisler, J., Voller, J., Gucký, T., Pospíšil, T., Spíchal, L., \& Strnad, M. (2017). Preparation, characterization and biological activity of $\mathrm{C}_{8}$-substituted cytokinins. Phytochemistry, 135, 115-127.

Zhang, X., Liu, W., Wang, J., Tian, H., Wang, W., \& Ru, S. (2018). Quantitative analysis of in-vivo responses of reproductive and thyroid endpoints in male goldfish exposed to monocrotophos pesticide. Comparative Biochemistry and Physiology. Part C: Toxicology and Pharmacology, 211, 41-47.

Zhou, B., Wang, H., Meng, B., Wei, R, Wang, L., An, C., Chen, S., Yang, C., \& Qiang S. (2019). An evaluation of tenuazonic acid, a potential biobased herbicide in cotton. Pest Management Science, 75, 2482-2489.

Zubrod, J.P., Bundschuh, R., Englert, D., Rohrberg, M. Wieczorek, M.V., Bakanov, N., Schulz, R., \& Bundschuh, M. Transient effects following peak exposures towards pesticides - An explanation for the unresponsiveness of in situ measured functional variables. Environmental Pollution, 231, 1393-1397. 